\title{
Impact of Power Outages on Residential Consumers in Riyadh City
}

\author{
A. M. ShaAlan \\ Electrical Engineering Dept., College of Engineering, \\ King Saud University, Riyadh, Saudi Arabia
}

\begin{abstract}
The effects of electric service interruptions resulting from severe power outages were investigated and analyzed. Two approaches have been developed and used. One is based on customers survey that mainly investigates the preparatory actions that a consumer may take to reduce the effects of outages. The other one is based on a mathematical model that focuses on the value of foregone leisure and ceased activities should outages occur in specific periods. The residential consumer in the city of Riyadh has been selected as a practical case to conduct this study. It has been found that this sector - which constitutes about $70 \%$ of the Saudi Consolidated Electric Company in the central region (SCECO-c) energy consumers - will suffer tangible and intangible losses should outages occur, particularly in summer time, and last for longer durations. This paper provides new information and data that can be used in a broad range of cost-benefit analyses in power system planning, design and operation.
\end{abstract}

\section{Introduction}

Electric service interruptions occur when system capacity, due to severe power outages, is insufficient to meet the system load levels. During these periods of inadequacy, outage costs will be borne by the utility, its customers and perhaps, by the entire society. The utility outage costs include loss of revenue, loss of future sales and increased repair expenditure and maintenance. These costs usually form only a small part of the total outages costs. The greater part is that borne by the consumers. The outage costs depend on many factors and situations, some of which are discussed in the following sections. The problem of estimating outage costs is affected by the perceived costs of an electric outage and the point in time when a consumer would like to 
buy electric energy but is unable to do so. Since there are different classes of consumers, each will tolerate loss of service differently. A residential consumer may suffer a great deal of hardship if an outage occurs during a hot summer day or while he is engaging in domestic activities but it may be of little inconvenience to a commercial user who is forced to close until power is restored. Also an outage may cause a great loss to an industrial user if it occurs during the time of the production process. Therefore, consumers do not perceive service interruption to the same degree of hardship.

The outage costs to a particular consumer depend also on the alternatives available to that individual at the time of service interruption. If the outages are not expected, the consumer may have very limited alternatives and may incur a great loss. On the other hand, if an adequate warning is given, the losses may be averted or mitigated. Also, as an outage continues or spreads to a larger subset of society, the society cost will tend to increase and will include such indirect costs as effects of anxiety, loss of products, food spoilage, health hazards, ... , etc. The major aspect of outage costs estimation is to assess the worth of power system reliability in order to compare it with the cost of power system so as to establish an appropriate system reliability level. In this regard, it is important to realize that, while the evaluation of power sytem reliability has become a well established practice over the last decade, the assessment of the worth of reliability or conversely, the estimation of costs of losses, which result from system unreliability, is still immature. The major reason for this is that quantification of interruption costs is an intricate and often a subjective task.

\section{Literature Review}

A review of the literature reveals numerous studies directed to estimate residential outage costs. Krohm ${ }^{[1]}$ considered that the impacts of outages upon residential consumer can be measured as the disruption of household preferred consumption pattern by time-of-day. A measure of the resultant reduction in the household welfare level due to inconvenience, loss leisure, ... etc., is its willingness-to-pay to avoid the outages. Koval and Billinton ${ }^{[2]}$ developed a statistical method and showed that the outage costs vary in a non-linear way with durations. Munasinghe ${ }^{[3]}$ considered that the main outage costs is the loss of evening leisure time which can be evaluated at the household income. The Swedish study ${ }^{[4]}$ was obtained by direct questioning to the customers and through worked examples based on actual losses, household activities, and leisure time. Wacker et al. ${ }^{[5,6]}$ and Billinton et al. ${ }^{[7]}$ used three survey approaches. Two of these approaches were considered with tariff changes that would be commensurate with specified changes in system reliability, while the third approach was concerned with the type of preparatory actions that consumers may take during outages periods. Also Billinton et al. ${ }^{[8]}$ relate the costs to the expected energy not served by using a frequency and duration approach and Mont Carlo simulation. Shaalan ${ }^{[9]}$ used a customer survey to estimate the outages costs for major customer's categories (i.e., residential, commercial, industrial). The method adopted was based on the customer's survey to assess damage that may result due to power outages. Corwin and Miles in their work ${ }^{[10]}$, discussed the impacts of power outages upon social life. Markel et al. study ${ }^{[11]}$ derived residential customer losses on the basis of the 
depreciation of all household electrical appliances for the duration of power outages. Lundberg ${ }^{[12]}$ discussed survey results from Swedish, French, and British utilities concerning customer's costs of power outages. These results were estimated on basis of lost leisure time and income rate. The monetary value was determined using average residential loads and occupancy. Sanghvi ${ }^{[13]}$ discussed the value of service (VOS) as an approach - which is based on customer choices regarding reliability worth and service costs - to be evaluated and incorporated into the planning process.

The data extracted from these studies are of significant contribution to the reliability-based power sytem planning ${ }^{[14-24]}$. These approaches, however, are not strictly comparable, the major reason being that the cases, scenarios, data, and modelling techniques are not identical.

\section{Consumers Response to Survey Questionnaires}

The objective of this work is to explore the impact of outages upon the residential sector in the city of Riyadh. Riyadh is the capital of Saudi Arabia and the largest city within the SCECO-c service area. The methodology used is shown in Appendix A. This methodology underwent an extensive developmental process. This involved an iterative approach consisting of the identification of factors to be included, design and development of the questionnaires and small scale testing of the questionnaires using interviews with sample users. A limitation to this approach is that long or frequent outages have not been experienced by the respondents and the nature and extent of the effects are unknown. It was concluded that the actual experience approach is not feasible and that the questionnaire design could assist respondents in making reasonable predictions as to the degree of the effects and what their perceptions and reactions might be.

The data used in this study is based on 512 responses selected from 626 questionnaires. The selected survey involved samples of residential consumers in Riyadh city. The respondents were asked to provide information concerning their views toward supply reliability, outages, occurrences, quality of service offered, degree of hardship and discomfort as a result of service interruptions, the customer willingness-to-pay to avert an outage(s), impact of service interruptions at critical periods such as evenings, leisure times and summer where the peak load normally occurs, their types of dwellings and their wages and sources of incomes. All respondents in the survey indicated that supply is reliable with one or two outages lasted only for short durations. Also, majority have agreed that the present tariff is reasonable. A direct estimate of outage costs was obtained by asking consumers to perceive the hardship and irritation of power outages and how much extra they would be willing to pay to avoid outages of different durations during summer time (questions 2 and 3). Many consumers indicated that, for outages within few minutes, no willingness to pay and that they would sit out the inconvenience rather than to pay, and for outages over one hour the tendency towards willingness to pay increases sharply as consumers were willing to pay large sums of money, i.e., the impact of outages upon the consumers welfare becomes substantial and intolerable (question 4). The daily leisure 
period during which electricity was considered valuable and occurred within the interval of 1830 to 2330 hours. Approximately 15 percent was devoted to dininng, 30 percent to television watching, 40 percent to family gatherings and entertaining guests and the remainder to other activities such as reading and conversing (question 5). The remaining questions (6-8) were mixed of attitudinal and demographic type of questions that seek information about the consumer, i.e., his attitude about the structure of current tariff, size and cost of electricity consumption, type of dwelling, size of family, net income. After having verified the importance of these information, some are exhibited in the following sections and some are used in the mathematical model that will be developed later.

\subsection{Residential Income vs. Electricity Consumption}

The basic unit for analyzing residential consumption was the average household of six persons. This mean household size of six persons was approximately constant over all income classes and was also assumed to remain unchanged in the future. Using SCECO's billing data as well as income data and average monthly consumption from residential survey, it was possible to plot the curve of average monthly household energy consumption against income as Fig. 1 shows.

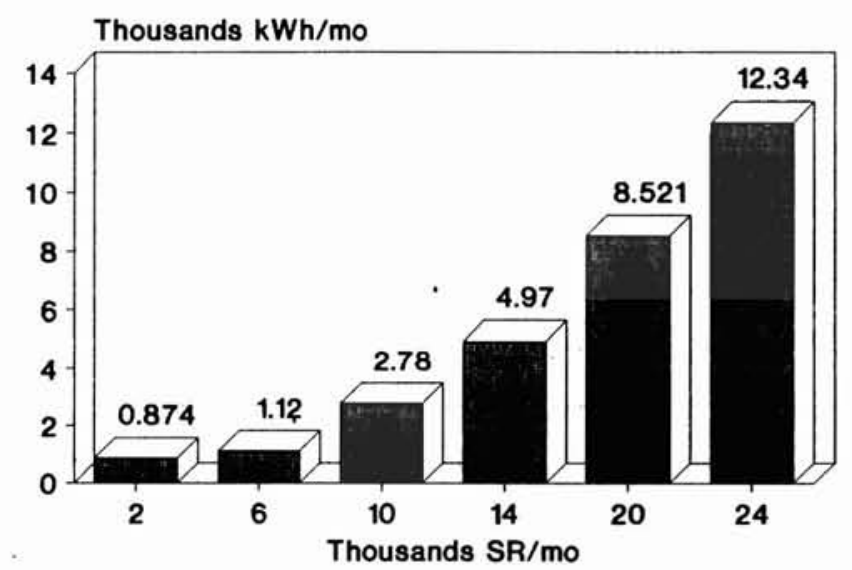

FIG. 1. Consumption (kWh) vs. income (SR/mo).

\subsection{Levels of Hardship with Outages}

To explore the extent of respondents' discomfort, anxiety and adversity during service interruptions, they have been asked to give, based on a scale varying from 0 (no hardship) to 5 (extreme hardship) their level of hardship of not being able to use major electrical appliances such as kitchen devices, washing machines, air conditioners, lights. Their responses are depicted in Fig. 2. It is noticed from the figure that the most critical devices that the residential consumers will not be able to use should an outage occur, are mainly air conditioners followed closely by loss of lighting and less closely by kitchen facilities and washing machines. 


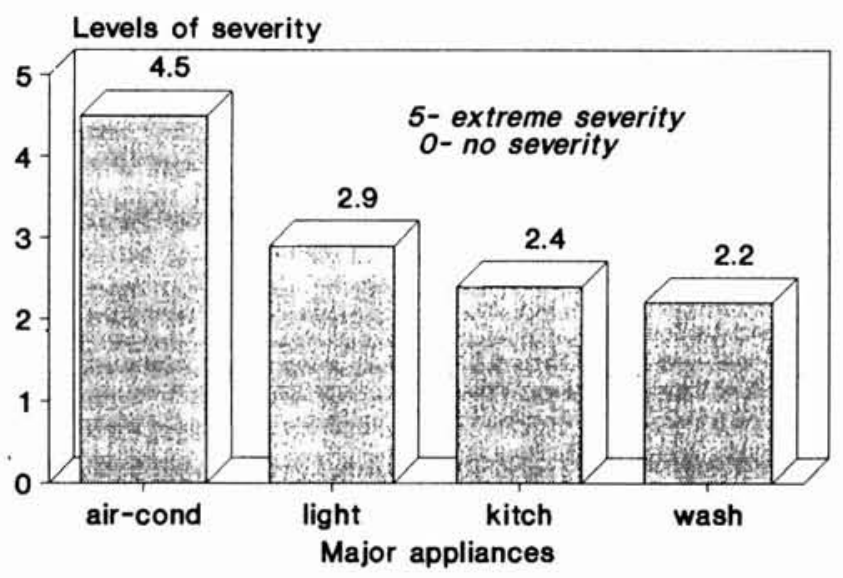

FIG. 2. Levels of severity with major appliances during outages.

\subsection{Cost Estimation Based on Customer's Perception}

Most of outages effects, as has been noticed (Fig. 2) are intangible and cannot be assessed in terms of monetary values and a single complete measure of the worth of reliability of supply to residential users is difficult if not impossible to obtain. The question which is appropriate to ask is: "What set of estimations should an analyst or a planner use as a criterion for reliability worth?". The answer depends on practical and theoretical structure of the analyses. In general, it is the author's opinion that one of the most suitable estimates of reliability worth is the customer's preparatory actions during outages and his willingness-to-pay to avert their occurrences. This approach is practically sound and more related to the perception of the residential customer and to his energy requirements. To seek the customer's readiness and type of preparatory actions that he takes against system failure, respondents were directed to suppose that they have been told by their power company that unexpected power outages will occur daily in summer time for various durations and asked to predict which action(s) they might take in preparation for the outages (Question 3). The costs quoted in the list of actions are used to compute an estimate of the cost of preparations that respondents indicate that they are willing to undertake to eliminate or at least to mitigate the adverse effects of the outages. Also, the survey aims to explore to what extent they are willing to pay to avert service cessation. Therefore, it is suggested (Question 4) that the power system has become subject to more frequent power outages. To increase system reliability, the company may add generating units and/or reinforce its network facilities which may result in tariff increase. Hence, the question postulates daily power outages in summer period for durations of $20 \mathrm{mi}$ nutes, 1 hour, 4 hours, and 8 hours. A range of possible tariff rate increases is proposed and the respondents are asked to perceive and assess the possible damage resulting from service interruptions and consequently to discern the fair and appropriate rate increases based on the prevailing present tariff structure. The data reported by the customers is exhibited by Fig. 3 . The survey results show that a signific- 
ant number of respondents were willing to pay higher rate for even up to $20 \%$ above the cost of the normal charge to avert prolong outage durations. The willingness-topay, however, becomes less when more rate increase is suggested or less frequent outages are proposed.

The cost per outage estimated as above are probably the most meaningful for the residential user group but the cost $/ \mathrm{kWh}$ and cost $/ \mathrm{kW}$ are determined as well for comparison with other studies and for planning purposes. These are presented in Table 1 and portrayed by Fig. 3. The SR/kWh estimates were obtained by weighting the respondent monthly energy consumption and payment and converted to a per outage basis to make the estimate consistent. The second part of the table lists the costs divided by the estimated peak demand which was determined from the user's one year consumption history by assuming a prevailing load factor of $19 \%$.

TABLE 1. Residential outage cost estimation.

\begin{tabular}{|c|c|c|}
\hline \multicolumn{3}{|c|}{ Cost / outage divided by monthly energy consumption (SR / kWh). } \\
\hline Outage & Action cost & Rate increase \\
duration & (SR) & (SR) \\
\hline $20 \mathrm{~min}$ & 0.00019 & 0.00016 \\
$1 \mathrm{hr}$ & 0.00098 & 0.00028 \\
$4 \mathrm{hr}$ & 0.00983 & 0.00414 \\
$8 \mathrm{hr}$ & 0.03211 & 0.02155 \\
\hline Cost / outage divided by monthly peak demand (SR/kW). & Rate increase \\
\hline Outage & Prep. cost & $($ SR ) \\
duration & $($ SR) & 0.185 \\
\hline $20 \mathrm{~min}$ & 0.002 & 0.320 \\
$1 \mathrm{hr}$ & 1.114 & 4.660 \\
$4 \mathrm{hr}$ & 11.535 & 24.380 \\
$8 \mathrm{hr}$ & 35.312 & \\
\hline
\end{tabular}

\section{Developed Mathematical Model}

The domestic activities are normally viewed as productive units but estimation of outage cost is not straightforward. This is because most of the "output" such as leisure, household activity are consumed within the household and cannot be assessed as monetary values. The most important household outputs that use electricity as a principal commodity are housekeeping, leisure and nutrition.

Consider a typical household that maximizes utility over some period of time. Utility $U$ is expressed as a function of leisure type $D$ that cannot be enjoyed without electricity and income $K$ (net of expenses incurred to enjoy the leisure, which represents all other consumption :

$$
U=U(D, K)
$$




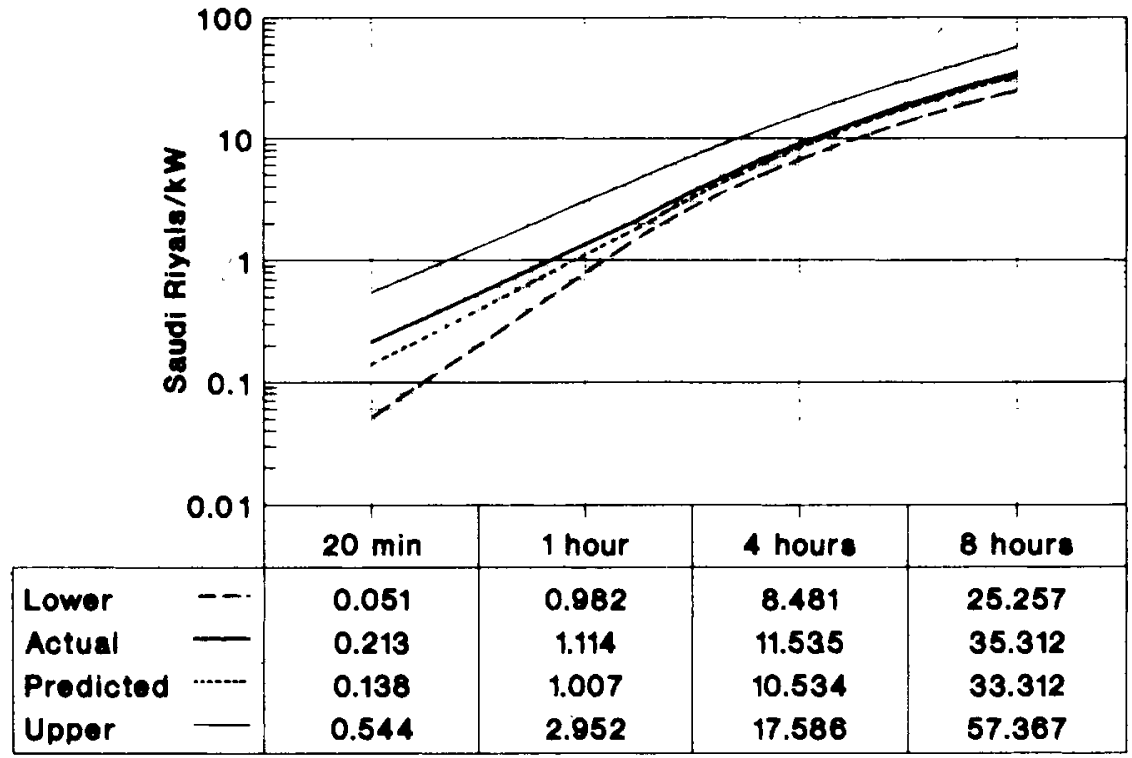

FiG. 3. Survey outage cost $(\mathrm{SR} / \mathrm{kW})$ vs. duration.

Next, leisure type $D$ is specified as a function of inputs, time $t$ (hours), electricity consumption $c(\mathrm{kWh})$, flow of services $s$ from the stock of electricity using air-conditioner and other input represented by $z$.

$$
D=D(t, c, s, z)
$$

Furthermore, $c$ and $s$ may be written as a functions of the stock of electricity using capital $i$, the value of appliances annuitized over their useful life, and of time $t$ which is a measure of intensivity of use. Therefore, $c=c(i, t)$ and $s=s(i, t)$. The household budget constraint may be written as

$$
K=w(H-t)-p \cdot c-b \cdot i-f \cdot z
$$

where $w=$ effective hourly net income earning rate; $H=$ maximum feasible number of hours of work in the time period; $p=$ mean price for each $\mathrm{kWh}$ of electric energy; $b=$ equivalent income foregone for each unit of $i$ in the same period; $f=$ cost for each unit of other inputs $z$ used.

Maximizing utility subject to the linear budget constraint is equivalent to unconstrained maximization of the expression

$$
L=U(D, K)-\lambda\left[H-t-\frac{1}{w}(K+p \cdot c+b \cdot i+f \cdot z)\right]
$$


The following equations indicate the first-order (necessary) conditions.

$$
\begin{aligned}
& \frac{\partial L}{\partial t}=\frac{\partial U}{\partial D}\left[\frac{\partial D}{\partial t}+\frac{\partial D}{\partial c} \cdot \frac{\partial c}{\partial t}+\frac{\partial D}{\partial s} \cdot \frac{\partial s}{\partial t}\right]+\lambda\left[1+\frac{p}{w} \cdot \frac{\partial c}{\partial t}\right]=0 \\
& \frac{\partial L}{\partial i}=\frac{\partial U}{\partial D}\left[\frac{\partial D}{\partial c} \cdot \frac{\partial c}{\partial i}+\frac{\partial D}{\partial s} \cdot \frac{\partial s}{\partial i}\right]+\frac{\lambda}{w}\left[p \cdot \frac{\partial c}{\partial i}+b\right]=0 \\
& \frac{\partial L}{\partial z}=\frac{\partial U}{\partial D} \cdot \frac{\partial D}{\partial z}+\frac{\lambda}{w} \cdot f=0 \\
& \frac{\partial L}{\partial K}=\frac{\partial U}{\partial K}+\frac{\lambda}{w}=0 \\
& \frac{\partial L}{\partial \lambda}=-\left[H-t-\frac{1}{w}(K+p \cdot c+b \cdot i+f \cdot z)\right]=0
\end{aligned}
$$

Multiplying equations $(1,2,3)$ by $d t, d k$, and $d x$ respectively, summing the three resulting equations, and rearranging terms yields

$$
\begin{array}{r}
\frac{\partial U}{\partial D}\left[\left(\frac{\partial D}{\partial t}+\frac{\partial D}{\partial c} \cdot \frac{\partial c}{\partial t}+\frac{\partial D}{\partial s} \cdot \frac{\partial s}{\partial t}\right) d t+\left(\frac{\partial D}{\partial c} \cdot \frac{\partial c}{\partial i}+\frac{\partial D}{\partial s} \cdot \frac{\partial s}{\partial i}\right) d i+\frac{\partial D}{\partial z} d z\right] \\
+\frac{\lambda}{w}\left[\left(w+p \cdot \frac{\partial c}{\partial t}\right) d t+\left(p \cdot \frac{\partial c}{\partial i}+b\right) d i+f \cdot d z\right]=0
\end{array}
$$

Simplifying further

$$
\frac{\partial}{\partial} \frac{U}{D} \cdot d D+\frac{\lambda}{w}(w \cdot d t+p \cdot d c+b \cdot d i+f \cdot d z)=0
$$

Dividing Eq. (6) by Eq. (4) yields an expression involving the marginal willingnessto-pay ( $M W T P$ ) for electricity dependent leisure, keeping utility constant as derived from the consumer's long run decision

$M W T P_{K, D} \cdot d D=w \cdot d t+p \cdot d c+b \cdot d i+f \cdot d z$

where

$$
M W T P_{K, D}=\frac{\partial}{\partial} \frac{U}{D} / \frac{\partial U}{\partial K}=-\frac{\partial K}{\partial} \frac{K}{U \text { constant }}
$$

By definition, $M W T P_{K, D}$ measures the marginal equivalent monetary value of electricity - dependent leisure; that is, it is the tariff increase that the consumer is willing to pay to just compensate for his leisure foregone due to electric service interruptions. Consider the effect of an unexpected outage during the evening when the family is enjoying leisure type $S$. During the outage, it can be argued that $c$ and $s$ depend only on $t$. This assumes a coherent type of relation between $i, c$, and $s$. For example, 
in any considered short period of time, electricity use may be linearly proportional to time. Therefore, it is possible to write

$$
c=\dot{\phi}(t)
$$

Using the above expressions to evaluate equation (7), and replacing $d D$ by $\Delta D$, and so on

$$
M W T P_{K, D} \cdot \Delta D=\left(w+p \cdot \frac{d \phi}{d t}\right) \cdot \Delta t+b \cdot \Delta i+f \cdot \Delta z
$$

Thus, the left side of Eq. (8) represents the overall welfare decrease because of an incremental loss of leisure $\Delta D$ resulting from the unexpected outage of duration $\Delta t$; the right side measures the value of the inputs necessary to produce the leisure. The term $(b \cdot \Delta i)$ is interpreted as representing the value of the input of electricity-using equipment that is foregone during the outage. If the income foregone in each period ( $b i$ ) is uniformly distributed over the leisure period $t$ during which the equipment is used, then the average value of appliance input for every unit of leisure time is $b i / t$, and therefore $b \cdot \Delta i=b .(i / t) \cdot \Delta t$. The household's electricity bill, however, will also be reduced by the amount $p$. $(\partial \phi / \partial t) . \Delta t$ from $\mathrm{kWh}$ not used during the outage. Therefore, the net incremental welfare loss or outage cost ( $O C$ ) may be written

$$
O C=M W T P_{K, D} \cdot \Delta D-p \cdot \frac{d \phi}{d t} \cdot \Delta t=w \cdot \Delta t+b \cdot \Delta i+f \cdot \Delta z
$$

Equation (9) measures the welfare change caused by an incremental change in the availability of electricty-dependent leisure $\Delta D$, in terms of the value of the inputs: $\Delta t, \Delta i$ and $\Delta z$ which are required to produce this leisure.

\subsection{Outage Cost Estimation Based on the Mathematical Model}

As mentioned in earlier discussion, residential outage cost is difficult to evaluate because of the nonmarketable nature of the household outputs produced by using electricity. Sometimes, data on wages and income are far easier to obtain than information on the use of appliances and other inputs. Fortunately in most cases the dominant factor in Eq. (9) is the income element. Look to Appendix B and take for example the air-conditioner, which is the most valuable appliance that a consumer could enjoy in a hot summer time. Assuming a purchase price of SR 1300 and a six year lifetime and a discount rate of $10 \%$, the annuitized value is SR 298 a year. For a device that is used 14 hours a day on the average, the corresponding value of $b . \Delta i$ is SR 0.44 an hour of outage, which is likely to be a negligible amount. Similarly, the term $f . \Delta z$ is also likely to be relatively insignificant.

It may be concluded that the difficulties of obtaining data on ownership of electrical appliances or other inputs used during leisure time will usually far outweigh any resulting refinement to the basic estimate of outage cost that is derived purely on the basis of more readily available income data. Therefore, in practice the following expression may be used as a good approximation to Eq. (9) 


$$
\Delta O C \lesssim w \cdot \Delta t
$$

In practical terms, there is an indirect link between the household activity and income summarized in Eq. (10) and as shown in earlier in Fig. 1. The outage costs and family income are positively correlated. This is a principal advantage of using foregone leisure and lost household activities to estimate the outage cost of residential consumers where the availability of easy-to-obtain income data. Often a good correlation between family income and energy consumption could be obtained by survey questionnaires (Appendix A). The theoretical outage cost has been estimated as displayed in Fig. 4.

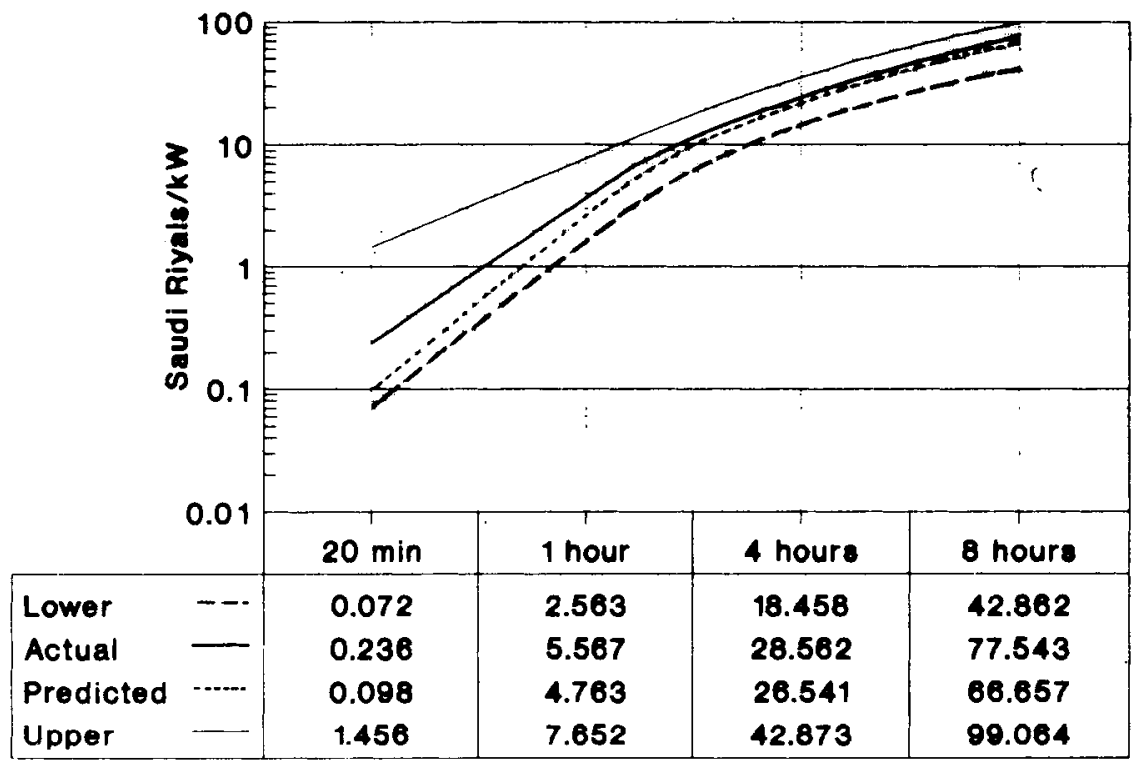

FIG. 4. Theoretical outage cost (SR/kW) vs. duration.

\section{Comparison of Survey and Theoretical Results}

In this research, two main approaches were attempted. The first one involves the choice of valuation methodology; two were considered and discussed. An obvious approach is a rate increase approach, wherein respondents were asked what increase in tariff rate they are willing to pay to avoid outages for various outage durations. The direct worth evaluation approach asks consumers to place a monetary value on the effects of certain interruptions scenarios or to assess the worth to them of not having to experience an interruption. This approach may suffer from the difficulty residential respondents encountered when attempting to give a meaningful answer to direct evaluation questions. This difficulty stems from the lack of respondent experience with markets in which intangible benefits, such as electric service reliability, are exchanged as a commodity. The most serious drawback with this approach is the antagonism many customers have towards price increase, especially those related to es. 
sential services such as electrical supply. Another drawback is that some respondents think that electric companies should provide a reliable and less costly supply as they feel that electric sector is heavily subsidised by the government. Another approach which has been developed and used is based on a mathematical model. This model can decrease the size of the problem associated with consumer lack of experience in rating the worth of service adequacy. Results of both approaches have been selected and plotted, as Fig. 5 displays, for comparison reason. The curves show some discrepancy which may be ascribed, in the questionnaires results, to the infrequent outage occurrence and subsequently less enthusiasm on part of consumers to respond to outages in buying emergency items or taking any precautionary actions. The model results seem to be higher and this also could be ascribed to the electricity-dependence weight embodied in the estimate due to the link between the use of energy and the per capita income.

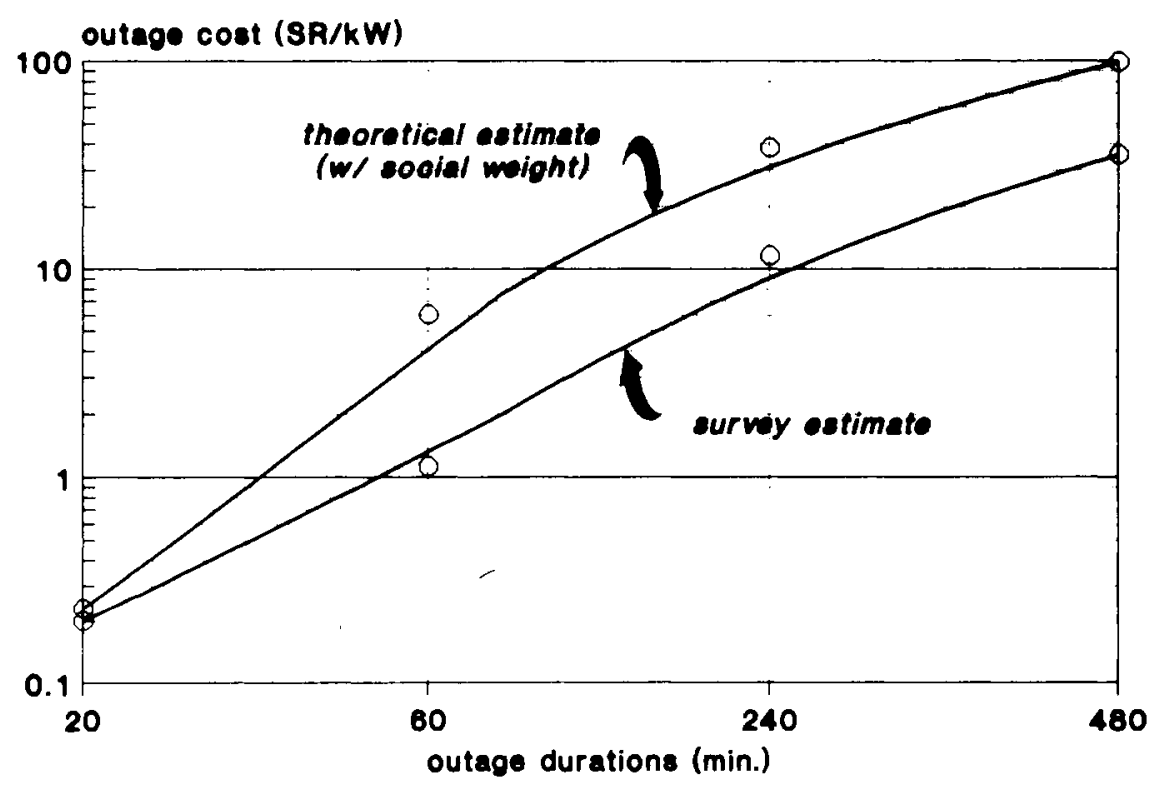

FIG. 5. Comparison of results of the two methods proposed.

\section{Conclusion}

This paper has presented results of research conducted to assess the perceived losses incurred by the residential sector in the city of Riyadh due to severe electric power outages. It has focussed on the development and implementation of practical and theoretical tools for evaluating an essential factor for the reliability of a power system with explicit consideration of consumer outage costs. The results reveal that these outages result in customer's deprivation from social activities, usage of certain essential appliances, and food spoilage. This causes customer's discomfort and anxiety both of which are intangible losses and cannot be quantified in monetary values. 
Two approaches, based on customer's losses incurred during outages and his willingness-to-pay to avert these outages, have been developed to estimate the customer's perceived costs should outages occur in specific periods and last for longer durations. The figures obtained for the costs imply a time-dependent non-linear outage cost. One major contribution of this paper is the development of useful tools for system planners, that enable them to incorporate consumer perception and preference in their assessment. Another contribution of this paper is the compilation of residential cost of outages data which can be used as a key input to reliability-cost evaluation in power system planning as demonstrated in Appendix C.

\section{References}

[1] Krohm, G., A survey of disruption and consumer costs resulting from a major residential power outage, Argonne National Laboratory Report No. ANL/EES-TM-29, Argonne, III., USA (1978).

[2] Koval, D. and Billinton, R., Statistical and analytical evaluation of the duration and cost of consumers interruption, IEEE Winter Power Meeting, Paper No. A76 057-1 (1979).

[3] Munasinghe, M., The costs incurred by residential electricity consumers due to power failures, Journal of Consumer Research, 6: 361-369 (1980).

[4] Swedish Electricity Association, Cost of Electric Supply Interruptions, Report Transmitted by the Government of Sweden to the Committees on Electric Power of the Economic Commission for Europe, No. EP/SEM,. 8/R30 (1981).

[5] Wacker, G., Wojcznski, E. and Billinton, R., Interruption cost methodology and results - a Canadian residential Survey, IEEE Trans., PAS, 102(10): 3385-3392 (1983).

[6] Wacker, G. and Billinton, R., Customer cost of electric service interruption, IEEE Proceedings, 77(6): 919-930 (1989).

[7] Billinton, R., Wacker, G. and Subramaniam, R., Factors affecting the development of residential customer damage function, IEEE Trans. on Power Systems, 2(1): 204-209 (1987).

[8] Billinton, R., Wacker, G. and Wojczynski, E., Customer Damage Resulting from Electric Service Interruptions, 1, R \& D, Project 907 U 131 Report (1982).

[9] Shaalan, A.M., Electric service interruptions: impact and cost estimation, Electra Cigrè, 127 (December): 99-109 (1989).

[10] Corwin, J. and Miles, W., Impact Assessment of the 1977 New York City Blackout, Department of Energy, Washington, D.C., USA, Conference for the Reliability of Electric Power Industry, pp. 193201 (1978).

[11] Markel, L., Ross, N. and Badertscher, N., Analysis of Electric Power System Reliability, Publications of Systems Control Inc., California Energy Resources Conservation and Development Commission, October (1976).

[12] Lundberg, L., Report of the group of experts on quality of service from the customer's point of view, International Union of Producers and Distributors of Electric Energy, (IUPDEE), Report No. 60/D. 1. (1972).

[13] Sanghvi, A., Measurement and application of customer interruption cost/value of service for cost-benefit reliability evaluation, IEEE-Trans. on Power Systems, 5(4): 1333-1344 (1990).

[14] Allan, R.N. and Shaalan, A.M., Cost benefit and reliability assessment of electrical generating systems, Reliability Engineering Int. Journal, 3(1): 1-19(1986).

[15] Shaalan, A.M., Problems associated with power system planning in developing countries, The Journal of Engin. Sciences, King Saud University, 14(2): 385-397 (1988).

[16] Shipley, R.B., Patton, A.D. and Denison, S., Power system reliability cost vs. worth, IEEE Trans., PAS 91: 2204-2212 (1972).

[17] Billinton, R. and Oteng-Adjei, J., Utilization of interrupted energy assessment rates in generation and transmission system planning, Transactions on Power Systems, 6(3) August: 1245-1253 (1991).

[18] Sullivan, R., Worth of Reliability, EPRI Workshop Proceedings, No. WS 77 60, pp. 6-40, 6-50 (1978). 
[19] Juseret, R., Reliability criteria used in various countries, Electra Cigrè, 110: 67-101 (1987).

[20] Munasinghe, M., New approach to power system planning, IEEE Trans., PAS, 99: 1198-1209 (1980).

[21] Allan, R.N. and Shaalan, A.M., Probabilistic production costing model, The Int. Journal of Modeling and Simulation, 8(3): 88-93 July (1988).

[22] Burns, S. and Gross, G., Value of Service Reliability, IEEE-Trans. on Power Systems, 5(3): 825-834 (1990).

[23] Sanghvi, A., Optimal electricity supply reliability using costomer shortages costs, Energy Economics, 5: 129-136 April (1983)

[24] Munasinghe, M., The Economics of Power System Reliability and Planning, John Hopkins University Press, pp. 62-71 (1979).

\section{Appendix A: Residential Survey Questionnaire}

\section{Q (1) Consumer's Experience with Supply Quality and Outages Occurrences During the Last Two Years}

(a) how you rate (circle one) electric service quality ( 0 inadequate- 6 Excellent)?

$\begin{array}{lllllll}0 & 1 & 2 & 3 & 4 & 5 & 6\end{array}$

(b) how many outages occurred?
(one
two
three
four
more

(c) what sorts of problems that were caused by $\overline{\text { outages? }}$
(social
safety

(d) how many times outages exceeded?
$(20 \mathrm{~min}$
1 hour
8 hours
24 hours

monetary

(e) have outages caused any anxiety such as loss of leisure, disruption to housekeeping activities, or food spoilage? Explain.

\section{Q (2) Inability to use major appliances during outages}

This question asks you to assess the extent and size of hardship as unexpected outages may deprive you from using major appliances. A scale of 0 to 5 is used to indicate various degrees of hardship from 0 meaning "no hardship effect" to 5 being "extreme hardship".

$\begin{array}{lllllll}\text { (a) Kitchen facilities } & 0 & 1 & 2 & 3 & 4 & 5 \\ \text { (b) Washing m/cs } & 0 & 1 & 2 & 3 & 4 & 5 \\ \text { (c) Air-conditioner } & 0 & 1 & 2 & 3 & 4 & 5 \\ \text { (d) Lighting } & 0 & 1 & 2 & 3 & 4 & 5\end{array}$

\section{$Q$ (3) Losses Resulting from Lasting Outages and Certain Preparatory Actions}

This question explores certain preparatory actions taken by the consumer as outages occur and last for longer durations. These actions attempt to mitigate the effects of outages. The list of possible preparatory actions are :

1. Make no preparations and live up with outages.

2. Use candle with costs of SR 1 each per hour to burn.

3. Use an emergency lamp or flashlight that would cost SR 1.5 per hour to buy and operate.

4. Use an emergency propane stove for home cooking which cost SR 2 per hour to buy and operate.

5. Use a gas refrigerator or freezer to keep meat and produce fresh which would cost SR 4 per hour to buy and operate.

Now chose and circle the appropriate preparatory action(s) as listed above that you may take to lessen the effects of the outages if they last for the following durations : 


$\begin{array}{llllll}20 \text { min } & 1 & 2 & 3 & 4 & 5 \\ 1 \text { hour } & 1 & 2 & 3 & 4 & 5 \\ 4 \text { hours } & 1 & 2 & 3 & 4 & 5 \\ 8 \text { hours } & 1 & 2 & 3 & 4 & 5\end{array}$

\section{Q (4) Proposed Tariff Increase to Avert Outages}

This question seeks consumer's opinion concerning the cost of electricity versus power outages. So, it proposes range of possible percentage increases in the present tariff that the consumer is willing to pay for different outage durations (circle the appropriate \%) :

\begin{tabular}{lllllll}
$\quad$ daily outage duration & & & \multicolumn{4}{c}{$\%$ tariff increase } \\
20 min & 5 & 10 & 20 & 30 & 40 & 50 \\
1 hour & 5 & 10 & 20 & 30 & 40 & 50 \\
4 hours & 5 & 10 & 20 & 30 & 40 & 50 \\
8 hours & 5 & 10 & 20 & 30 & 40 & 50
\end{tabular}

\section{Q (5) Activities During Evening Leisure Hours}

On average, how do you spend your evening/night leisure hours?
(a) Social gatherings
(b) Reading/writing
(c) Having dinner
hours
(d) Watching TV, video/listening to radio

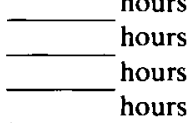

$Q$ (6) Electric Tariff and Energy Consumption

(a) Indicate what you think about the present electric tariff : low reasonable high

(b) What was your average monthly electricity consumption and charges (only during summer season): $(\mathrm{kWh} / \mathrm{mo})$ (SR/mo)

\section{Q (7) Dwelling Types}

Specify type of dwelling you presently occupy :
(a) Villa
(b) Duplex
(c) Apartment

$Q(8)$ Income Sources and Size

(a) What are your principal sources of income:

What is your average monthly income: ( $\mathrm{SR} / \mathrm{mo})$

(c) How many persons live in your household: - over persons

\section{Appendix B: Empirical Estimation of Major Appliances for the Theoretical Model}

Using the following equation for the annuity value of major household appliances :

$$
A=P\left[\frac{i(1+i)^{N}}{(1+i)^{N}-1}\right]
$$

where the annual discount rate, $i$ is $10 \%$ 


\begin{tabular}{|l|c|c|c|c|c|}
\hline \multicolumn{1}{|c|}{ Set } & $\begin{array}{c}\text { Price }(P) \\
(\text { SR })\end{array}$ & $\begin{array}{c}\text { Lifetime }(N) \\
(\text { years })\end{array}$ & $\begin{array}{c}\text { Annuity ( } A \text { ) } \\
(\text { SR })\end{array}$ & $\begin{array}{c}\text { Approx. } \\
\text { hourly use / day }\end{array}$ & $\begin{array}{c}\text { Cost / hour } \\
\text { (SR ) }\end{array}$ \\
\hline Fregerator & 1500 & 10 & 244.12 & 20 & 0.557 \\
Elec. range & 2500 & 8 & 468.61 & 6 & 0.321 \\
Air-cond. & 1300 & 6 & 298.48 & 14 & 0.447 \\
TV & 1900 & 7 & 390.27 & 10 & 0.446 \\
Washer & 1200 & 5 & 316.56 & 5 & 0.181 \\
Cleaner & 700 & 4 & 220.83 & 4 & 0.100 \\
\hline
\end{tabular}

Appendix C: Relationship between Energy, Outages, Reliability and Costs.
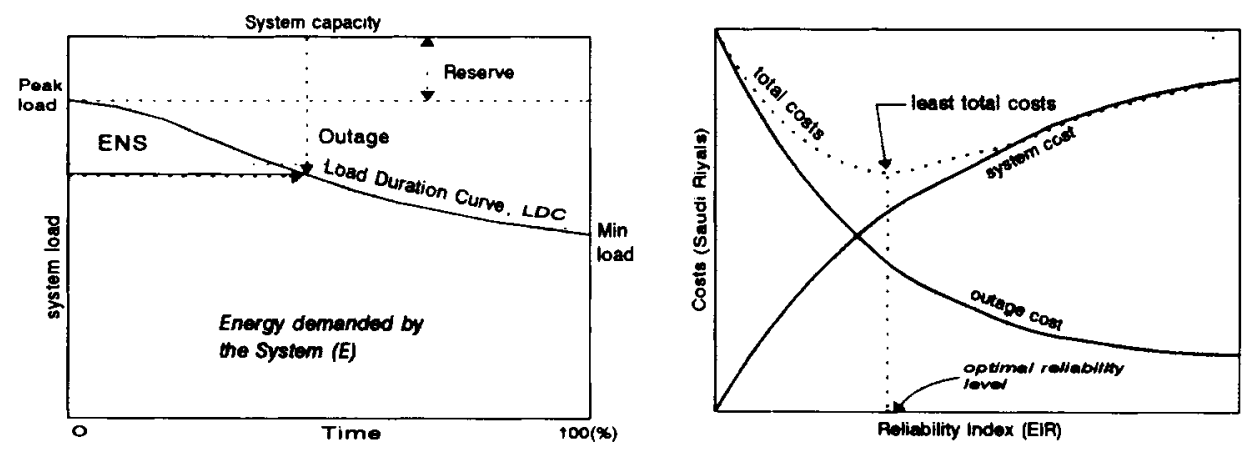

The multiple Energy Not Served ( $E N S_{i}$ ) can be evaluated as

$$
E N S_{i}=\left(O_{i}-R\right) \cdot t_{i} \quad\left(O_{i}>R\right)
$$

Since outages occurrence is of probabilistic nature, therefore, the accumulated Expected Energy Not Served ( $E E N S$ ) which may be used for planning purposes (i.e., economic assessment or reliability. evaluation) can be evaluated as

$$
\begin{gathered}
E E N S=\sum_{i} E N S_{i} \cdot p_{i} \quad \mathrm{kWh} / \text { period } \\
\text { where }, p_{i}=\text { probability occurrence of the } i \text { th outage }\left(O_{i}\right)
\end{gathered}
$$

Therefore, the outage cost ( $O C$ ) for a specific planning period (say 1 year) can be estimated as

$$
O C=E E N S \cdot(\operatorname{cost} / \mathbf{k W h})
$$

where, cost / $\mathrm{kWh}$ can be designated based on the techniques presented.

A reliability index called Energy Index of Reliability, EIR, has received a considerable attention ${ }^{1,2}$ and can be evaluated as

\footnotetext{
${ }^{1}$ R. Billinton and R. Allan, Reliability Evaluation of Power Systems, Plenum Press, New York, pp. 56-64 (1986).

${ }^{2}$ R. Billinton and R. Allan, Reliability Assessment of Large Electric Power Systems, Kluwer Academic Publishers, Boston, pp. $45-48$ (1988).
} 


$$
E I R=1-\frac{E E N S}{E}
$$

The EIR measures the risk level that can be assigned for planning criteria. 
تأثــير انقـطاعات الحدمــة الكهربائية على المستهلك السكني بمدينـة الرياض

\author{
عبد الهه محمد الشعلان

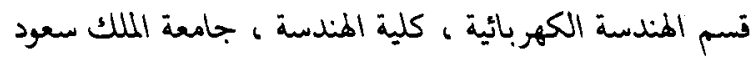

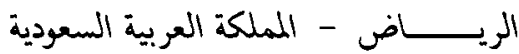

المستخلص · تم تحري وتحليل آثـار انقـطاعات الحدمة الكهربائية الناجمة عن تعطل

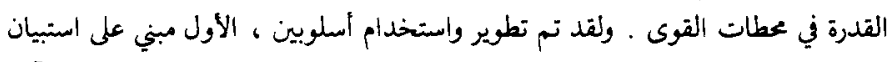

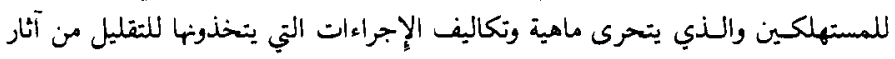

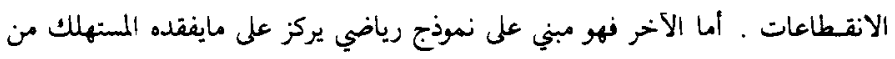

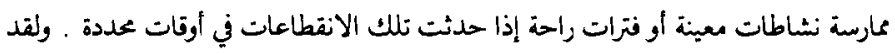

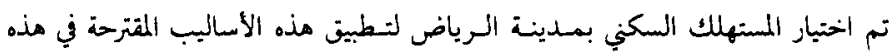

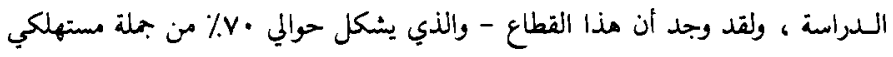

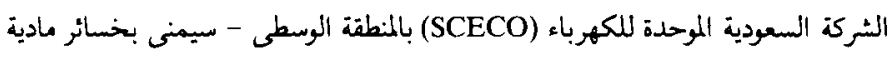

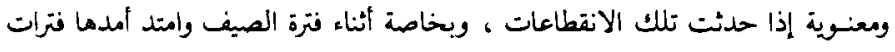

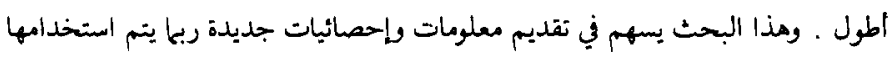

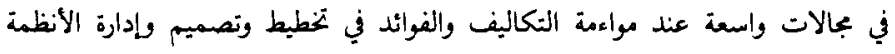
الكهربائية 